\title{
El acierto en el fracaso. La revista Imán (1931), un episodio de la historia literaria latinoamericana
}

\section{The Succes in Failure. The Journal Imán (1931), an Episode of the Latinamerican Literary History}

\section{Resumen}

En este trabajo pretendemos poner de relieve que la fugacidad de la revista Imán, que apareció en París en 1931, editada por la argentina Elvira de Alvear (1907-1959) no mermó su capacidad en cuanto a los objetivos literarios que se había propuesto. Imán acertó cuando difundió fragmentos de obras de quienes formarían parte de la renovación de la prosa latinoamericana del siglo XX: Alejo Carpentier, Miguel Ángel Asturias y Arturo Uslar Pietri.

Palabras claves revista, París, narrativa latinoamericana, Carpentier, Asturias, Uslar Pietri.

\begin{abstract}
In this work we intend to highlight that the fleetingness of the magazine Imán, which appeared in Paris in 1931, edited by Argentina's Elvira de Alvear (1907-1959), did not diminish its capacity in terms of literary goals that had been proposed. when he disseminated fragments of works by those who would be part of the renovation of the Latin American prose of the 20th century: Alejo Carpentier, Miguel Ángel Asturias and Arturo Uslar Pietri.
\end{abstract}

Keywords magazine, Paris, Latin American narrative, Carpentier, Asturias, Uslar Pietri. 


\section{Introducción}

El oxímoron que encabeza este trabajo -el acierto en el fracaso- tiene que ver con algunos proyectos editoriales que aún en su malogro, por la falta de continuidad como es el caso de una revista de la que solo aparece un número, puede realizar un singular aporte a la historia de la cultura latinoamericana. En las páginas que siguen intentaremos demostrar que la fugacidad de la revista Imán, publicada en París en 1931 por la argentina Elvira de Alvear (1907-1959) es inversamente proporcional a la eficacia lograda de acuerdo con su propuesta editorial. Imán acertó cuando difundió fragmentos de obras de quienes formarían parte de la renovación de la prosa latinoamericana del siglo XX: Alejo Carpentier, Miguel Ángel Asturias y Arturo Uslar Pietri. Los tres latinoamericanos compartieron un tiempo y espacio cultural común en París. Asturias había llegado en septiembre de 1924; el venezolano Uslar Pietri en 1929; Carpentier a fines marzo de 1928 y permanecería hasta 1939. Se trata de uno de esos episodios inesperados de la cultura que tiene después desenlaces de alcances insospechados como por ejemplo que la "máquina de escritura" que ha sido París ${ }^{1}$ intervenga en los cambios cruciales del arte latinoamericano.

De manera que esta revista guarda especial interés por diversos motivos. En primer término, porque en sus páginas reproduce textos de los tres intelectuales mencionados, circunstancia que no se repite en ninguna otra publicación, hasta donde sabemos. Los textos difundidos además visualizan el dilema que estos

${ }^{1}$ París fue la meca de los intelectuales latinoamericanos desde el siglo XIX en adelante. La idea de que en esa ciudad era factible la consagración como escritores tuvo diversos efectos que van de los meramente testimoniales a los verdaderamente triunfantes. Bastaría consignar entre los proyectos triunfantes los nombres de Rubén Darío a Mario Vargas Llosa, para tomar un arco extenso. En tal sentido, París deja de ser solamente una sede exclusivamente espacial para transformarse en un dispositivo que incluye tanto experiencias reales como deseos inalcanzables. Si se la puede llamar "máquina de escritura" es porque los latinoamericanos con aspiraciones literarias debían ejercitar, con mayor o menor acierto, la practica escrituraria casi de manera imperativa para alcanzar los objetivos que se habían propuesto. 
escritores deben resolver si quieren superar la novela telúrica latinoamericana. En otras palabras, necesitan desarrollar una práctica narrativa que facilite la ampliación de los límites del realismo de finales del siglo XIX y comienzos del XX. Ellos son contemporáneos de los grandes representantes de la novelística de la tierra: José Eustasio Rivera, Rómulo Gallegos, Ricardo Güiraldes, autores respectivamente de La vorágine, Doña Bárbara y Don Segundo Sombra. Estas novelas recibieron la denominación de ejemplares y constituyeron, por el grado de difusión alcanzado, el "primer boom" latinoamericano.

En un interesante texto de Beatriz Sarlo sobre intelectuales y revistas, la ensayista argentina nos hace notar el envejecimiento de las revistas y la desactualización en la que se sumergen luego de perder ese "aura" que las caracterizó durante su vigencia. En tal sentido, la revista resulta más un objeto de deseo de sus productores que de los lectores actuales (Sarlo 10). Es verdad, sin embargo, en el caso que nos ocupa, aun siendo evidente el "fracaso" de Imán, por el hecho de que no pudo sacar más que un número, es solamente de orden financiero. Carmen Vásquez describe de esta manera la fugacidad de la revista, aunque reconociendo su "éxito":

El éxito de la revista Imán fue certero. Amigos y colaboradores se reunían con motivo de su publicación, sobre todo, en casa de Elvira de Alvear. Acudían también otros, que aún no habían colaborado, recién llegados a París, como Rafael Alberti y el folklorista Tata Nacho. Ya se programaba el segundo número. Este incluiría, además de largos fragmentos del libro que sobre André Gide escribía Léon Pierre-Quint, Residencia en la tierra del joven y aún desconocido chileno Pablo Neruda. Pero ya la crisis económica se hacía sentir en ambos lados del Atlántico. Un día, Elvira de Alvear recibió la noticia: la Argentina acababa de dictar una ley contra la exportación de capital. Sin otra alternativa, tuvo que regresar a Buenos Aires, y así, suspender la 
publicación de la revista que tanto había esperanzado a los jóvenes escritores de esa generación. (Vásquez 109)

Si Imán fue una "apuesta perdida”, como dice Sarlo, se recupera lo perdido -en tanto fracaso de la continuidad- en algunos contenidos volcados en sus páginas. De manera contrafáctica se podría preguntar qué hubiera ocurrido si la revista continuaba. Vale la pena echar un vistazo al índice del segundo número para darnos cuenta de ello. ${ }^{2}$ Lo cierto es que la revista consiguió introducirse en la problemática que definía aquel presente parisino de las vanguardias. Jorge Schwartz demostró que la historia de las vanguardias podía hacerse a partir de las revistas o que los modelos de modernización cultural en América Latina tuvieron a las publicaciones periódicas como el escenario de las diversas posiciones (Sarlo 11). Imán es consecuencia de una coyuntura, está claro; pero de manera consciente o no, se propuso intervenir en ella con un aporte notable. Sarlo, por su lado, pone como ejemplo la construcción del concepto de "nueva novela latinoamericana", en los años 60 del siglo pasado, impulsada por Ángel Rama en la revista Marcha, aún a

${ }^{2}$ El segundo número quedó sólo en galeradas. Se conserva el índice: Macedonio Fernández (texto incompleto cuyo título no aparece) [CG: P. 9-28]; León Paul Fargue. Nacimiento (Naissances), texto bilingüe (traducción de Elvira de Alvear). P. 31; Stefan Zweig. El libro como introducción al conocimiento del mundo (traducción de E. Salazar S.). P. 37; Leo Ferrero. París y la pasión de los principios (traducción de Alejo Carpentier). P. 45; Jules Supervielle. El alba (L'aube), texto bilingüe (versión española de M. Altolaguirre), P. 58; La pájara pinta. Guirigay lírico-bufobailable para marionetas. (No se refleja el nombre del autor, pero se trata de Rafael Alberti. Aparece solamente la primera página con los dramatis personae). P. 64; Emmanuel Berl. El burgués y el amor. Traducción de F. de M.1 P. 113; Luis Cardoza y Aragón. Martirio de San Dionisio. P. 128; Miguel Ángel Asturias. Emilio Lipolidón. P. 135; León Pierre Quint. El régimen celular: la familia y la educación. Traducción de Félix Rodríguez. P. 146; Pablo Neruda. La noche del soldado. P. 171; Pablo Neruda. Juntos nosotros, Monzón de Mayo, Alianza, Sistema Sombrío. P. 173; Alberto Hidalgo. Acta de paso, Brújula de sangre, Exégesis de incógnito, Circunvalación por esto. P. 178. Alberto Hidalgo. Exégesis para que tampoco se entienda. P. 181; Jorge Guillén (texto incompleto). Playa (niños), Oleaje, Playa (indios), Arena, El aparecido. P. 209; Mariano Brull. Dos poemas: Epístola y Blanca de nieve. P. 215; Manuel Altolaguirre. Poemas: I, II, III (Amor), IV, V (A mi madre); Raymond Queneau (texto incompleto). Comprender la locura. P. 222; Le Corbusier (texto incompleto cuyo título no aparece). P. 257; George Duhamel. Palabras pronunciadas por el autor en su jardín de Valmondois y reproducidas con su autorización. Luc Durtain. Estos últimos siglos de historia... P. 263; Jean Cassou. Para los franceses, la idea latina ... P. 265; Marius François Gaillard. Mi pensamiento inquieto... P. 267. Jesús Cañete Ochoa halló estos datos en Cuba y los consignó en su Tesis "La primera narrativa de Alejo Carpentier" (2015) 
sabiendas de que el radio en el que la revista incidía era muy reacio a dicha noción. (11) El ejemplo es muy acertado, pero para que llegara a forjarse una noción de una nueva novela latinoamericana existió un proceso anterior en el que tuvieron especial importancia las vanguardias y, por tanto, publicaciones como la de Imán, entre tantas otras.

En el proceso de constitución del recorte llamado "nueva novela latinoamericana", Imán tiene ganado un lugar, acotado, pero no menos relevante. Desde ahí que, en cierto modo, la revista eluda lo que otras no hicieron, esto es, correr el riesgo, por una actitud anticipadora, de errar en sus "predicciones" o acertar en las intuiciones "futuras" (Sarlo 11). A veces, ello se debe a una "historia de la lectura" de los textos que se relacionan con las limitaciones ideológicas y estéticas de su tiempo (11). Estos factores convierten a las revistas en más o menos visibles, es decir que crean más o menos públicos propios. Imán no impone la renovación de la prosa latinoamericana, sino que más bien se ubica en un espacio intersticial, en el que realiza una contribución a ello dentro de un contexto metropolitano (ya veremos que este aspecto es destacable) dominado por las vanguardias. Imán se ocupó más de "mostrar" los textos que irían a contribuir al proceso de cambio que a "publicarlos", como bien distingue Sarlo (11). En tal sentido, al haber "mostrado" los textos que iniciaban una renovación de la novela latinoamericana, Imán padece de un fracaso editorial pero, por otro lado, de un éxito al aportar a la formación de un público lector que iría a renovar sus parámetros de lectura y prepararía los dominios del cambio estético en la narrativa. (Sarlo 15)

\section{Una gramática de Imán}

La editora quiso sumarse al movimiento emprendido por otras mujeres latinoamericanas, como el de su compatriota Victoria Ocampo, quien había fundado tres meses antes en Buenos Aires la revista Sur (1931). Imán comparada con Repertorio Americano, Sur o Nosotros es insignificante. Sin embargo, si la 
situamos en el conjunto de revistas que tuvieron una sola edición y ello no es una excepción sino consecuencia de funcionamientos editoriales, la valorización varía. Si analizáramos a contrapelo -como proponía Walter Benjamin para comprender mejor la historia en general- la historia de las publicaciones periódicas que tuvieron notables éxitos, por la continuidad y calidad de sus textos, encontraríamos casos como los de la revista Imán, que confirman la regla del éxito. Al fin de cuentas seguimos al historiador Ginzburg para quien "[...] las excepciones siempre son más interesantes que la regla [...] La regla no puede contener todas sus excepciones, pero las excepciones sí contienen a la regla. Por eso son más ricas por todo lo que se puede extraer de ellas" (2018). El fracaso desde el punto de vista de la continuidad no puede ocultarnos el acierto en la formación de un episodio singular de la cultura latinoamericana. Nada es más sencillo y entusiasta que un grupo de intelectuales se reúna y exprese su deseo de "crear una revista". El entusiasmo y la factibilidad, no obstante, permanecen siempre y cuando se resuelvan varias cuestiones estructurales: los recursos financieros, la unidad de objetivos, la aceptación del reparto de responsabilidades y roles, la captación de textos relevantes y finalmente la conquista de un público lector por medio de la distribución y venta. Estos vectores que estructuran cualquier publicación se cumplieron en Imán, con la única salvedad de que Elvira de Alvear era directora y mecenas. Elvira como buena representante de la alta burguesía argentina vivía de rentas; al prohibirse la salida de capitales en Argentina se vio obligada a abandonar Europa, como ya se dijo. Por lo tanto el componente financiero determinó la finalización de la revista. Asimismo, habría que hacer otra salvedad: en el proyecto Imán no existió un grupo de intelectuales dispuestos a crear una revista literaria, sino que el proyecto fue unipersonal, esto es, pertenecía a Elvira de Alvear. Es una revista que forma parte de las que han producido 'desvíos' con relación a los parámetros esperados para las publicaciones periódicas. También podría verse como otra "anomalía" el hecho de ser una revista unipersonal en cuanto a su conducción. Un repositorio francés de revistas, para tomar un ejemplo, contabiliza 77 publicaciones que tuvieron un solo número (entre las que registra a Imán) y 37 
revistas unipersonales. Los números corresponden a diversas épocas del siglo XX (Revues litteraires).

Con todo, aquí no estamos haciendo valer la cantidad, periodicidad o trayectoria de una publicación, sino los aportes realizados en el campo de la cultura. Imán es insignificante por su continuidad, pero meritoria por lo que supo recoger. Es quizás una especie de fotograma del comportamiento cultural latinoamericano de los años 30 del siglo XX. Se comporta como dispositivo portador de lo nuevo o de lo que está por venir y, por otra parte, su editora resultó ser una hábil diseñadora de redes. Elvira alternó con Vicente Huidobro o Rafael Alberti, entre otros escritores hispano hablantes y Paul Valéry y James Joyce, entre los europeos. Estas redes y las que quedan de manifiesto entre quienes escriben para Imán, le dan a la publicación la fuerte impronta vanguardista. Para mayor abundamiento, lo dicho se constata en el título de la publicación que probablemente provenga de la influencia de Les Champs magnètiques (1919), de acuerdo con la interpretación de Gilberto Mendoça Tales y Kalu Müller Bergh, quienes reproducen el editorial de la revista Imán, como una especie de manifiesto (227). El libro Les Champs magnètiques fue publicado por André Breton y Philippe Soupault en 1920 y se considera el primer intento surrealista. Cabe agregar que Soupault está entre los colaboradores del único número de Imán. Los campos magnéticos esbozan el procedimiento creativo del surrealismo: el fluir libre del pensamiento sin la intervención de la razón. Se trata de una relación magnética entre facetas de la imaginación.

El único número de Imán, que se había propuesto ser trimestral, lleva la fecha de impresión el 30 de abril de 1931, en cuatro ediciones. El ejemplar de la Biblioteca Nacional de España lleva el número 2.622, de una edición de 2.500 impresos sobre papel Alfa Mouse, de las Papelerías de Navarre. La circulación de la entrega se llevó a cabo a través de la Librería Viau y Zona (Buenos Aires); Librería Española (París), de Juan Vicens de la Llave, y Librería Sánchez Cuesta (Madrid). El sumario completo de Imán, $\mathrm{n}^{\circ}$ 1, abril 1931 es el siguiente:

Elvira de Alvear, Imán, 
Léon-Paul Fargue, De una pluma a un Imán,

Jean Giono, Ese bello seno redondo es la colina,

Lascano Tegui, Mis amigas se murieron,

Xul Solar, Poema,

Bruno Barilli, La sonrisa de los siglos,

Vicente Huidobro, El paladín sin esperanza,

Henri Michaux, La noche de los búlgaros,

Jaime Torres Bodet, La visita,

Eugenio d'Ors, De la elipse en el misterio de lo barroco,

Robert Desnos, Lautréamont,

Franz Kafka, La sentencia,

Miguel Ángel Asturias, En las tinieblas del cañaveral,

Eugéne Jolas, Documento,

Benjamín Fondane, Ulises,

Sixto Martelli, Umbrales,

Alejo Carpentier, Ecue-Yamba-O,

Hans Arp, Dos poemas,

Boris Pilniak, La revuelta de las mujeres,

[Conocimiento de América Latina] Georges Ribemont-Dessaignes, Robert Desnos, Geogres Bataille, Michel Leiris, Philippe Soupault, Walter Mehring, Alfred Kreymborg, Zdenko Reich, Roger Vitrac, Nino Frank, John Dos Passos, ¿Qué quiere decir teatro?, A[rturo] Uslar Pietri, Las lanzas coloradas.

Imán recoge en un porcentaje muy alto textos de creación, desde poesía a la reflexión ensayística. Conviven textos bilingües con otros traducidos, la mayor parte son de escritores franceses, salvo Franz Kafka y John Dos Passos. La directora combina la procedencia de escritos en otras lenguas con los trabajos de autores latinoamericanos, pero que viven en París. En otras palabras, la lengua, sea francesa o no, lleva la traza parisina. Elvira de Alvear no puede resistirse a la modalidad de 
las encuestas a los escritores que las revistas elaboran en torno a un tema. En este caso, el tema es el "conocimiento de América Latina" que los escritores franceses tienen sobre ese continente. Son los miembros de "la joven literatura centralizada en París", representantes del surrealismo literario parisino. Las respuestas son dignas de tratarse, aunque no sea parte de nuestros propósitos, pero digamos que además de respuestas muy decepcionantes, estos escritores de la "joven literatura francesa" desconocen completamente América Latina o se valen de lugares comunes, estereotipados.

\section{El factor París en la identidad latinoamericana}

Mariano Siskind ha propuesto el "deseo mundo" como una estructura epistemológica para comprender la modernidad global y la literatura mundial en América Latina. Esta estructura resulta común a los discursos críticos y estéticos cosmopolitas (Siskind 15). París -como espacio y representación simbólicatambién funciona como una estructura epistemológica para pensarla tanto como una "máquina de escribir" como una experiencia identificatoria. De acuerdo con varios testimonios, los latinoamericanos "descubrían" esa condición en la capital francesa (Colombi). También las realidades nacionales o americanas reaparecían en la inspiración temática de algunos escritores latinoamericanos. Un caso notable será el de Ricardo Güiraldes, quien escribe en París una novela de la tierra, Don Segundo Sombra. París en él oficia como acicate de la escritura y el descubrimiento de una identidad. En el ambiente más cosmopolita, Güiraldes reconstruye un espacio nacional perdido. En la pintura, Pablo Picasso o Diego Rivera exploran los escenarios nacionales por parecidas razones, esto es, la estancia parisina. El cubismo aprendido por Rivera le posibilitó volver su mirada a México con otros ojos. En la capital francesa se publica, en 1926, La raza cósmica, el famoso ensayo José de Vasconcelos en el que desarrolla su tesis de la identidad americana como unión de tres razas. José Carlos Mariátegui recogió en Amauta, un texto de 
Vasconcelos titulado "Nacionalismo en América Latina" (1927), concebido también en la ciudad cosmopolita. ${ }^{3}$ Un caso anterior al mencionado se da en 1905 cuando Rubén Darío escribe "Salutación del optimista" y "A Roosevelt", poemas en los que exalta la raza latina y combate al imperialismo yanqui. De modo que el lugar de enunciación en la gramática editorial de Imán es muy significativo a juzgar por los casos mencionados anteriormente. París continúa siendo considerada la “capital cultural” europea (Rojas). Y ello presenta algunas problemáticas dignas de discutir, como el caso del redescubrimiento americano, los debates por la identidad, una identidad forjada a la distancia. La revista de la que nos ocupamos se sitúa entre las publicaciones de la vanguardia, pero en un momento en que están sucediendo por lo menos dos hechos de interés para nuestros propósitos.

Si París pudo ser una "máquina de la escritura", también lo fue de la identidad, como dijimos. Una identidad cultural de América Latina que se gestó en las primeras décadas del siglo XX fuera del continente. Desde el modernismo a las vanguardias el redescubrimiento de lo propiamente americano fue un efecto derivado de la vida en París. Este proceso cultural se produjo en diversos espacios de sociabililidad intelectual como salones y cafés especialmente parisinos. La lista de intelectuales y artistas que experimentan este mecanismo develador de identidades es amplia: Diego Rivera, José Vasconcelos, Wifredo Lam, Eduardo Abela, Marcelo Pogolotti, Félix Pita, Alejo Carpentier, Lydia Cabrera, Vicente Huidobro, Heitor Villa-Lobos, Miguel Ángel Asturias, Luis Cardoza y Aragón, Arturo Uslar Pietri, Max Jiménez, Victoria Ocampo, Teresa de la Parra, Aníbal Ponce y César Vallejo. Cabe aclarar que estos nombres corresponden a una segunda oleada durante el siglo XX. La primera había sido capitaneada por Rubén Darío y un número considerable de latinoamericanos: Rufino Blanco Fombona, Manuel

${ }^{3}$ París es el sitio de encuentro, inspiración y consagración de la escritura. Ciudad en la que se desarrollan o consolidan diversos movimientos artísticos en lengua hispana: el "Modernismo" Rubén Darío, la "Nueva narrativa" con Teresa de la Parra, el "Creacionismo" con Vicente Huidobro; con posterioridad el "realismo mágico" de Miguel Ángel Asturias ; el boom de los 70 con el colombiano Gabriel García Márquez, los argentinos Julio Cortázar y Marta Traba, el peruano Mario Vargas Llosa, el mexicano Octavio Paz; la "escritura del género femenino" de las décadas 80 y 90 con la mexicana Elena Garro y la colombiana Marvel Moreno. 
Ugarte, Amado Nervo, Enrique Gómez Carrillo, Horacio Quiroga, entre otros. Para unos y otros, las razones por las que arribaban a la "capital cultural" fueron diferentes. Esas motivaciones iban desde el exilio, la posesión de fortuna acompañada por la dilatancia, la búsqueda de la consagración como artistas, etc. La numerosa colonia americana no era homogénea. Se alternaban las grandes fortunas con exiliados, bohemios, artistas prestigiosos y fracasados. (Cheymol) Entre ambas camadas, la modernista y la vanguardista, se producen fenómenos similares en cuanto al significado que tuvo la estancia parisina. En lugar de profundizar algún eurocentrismo, cosmopolitismo o universalismo, desarrollaron una obra que fue al rescate de las dimensiones de la realidad americana que hasta entonces no habían sido completamente descubiertas e incorporadas a la literatura. Obra de afirmación nacionalista y regionalista con una proyección universal.

En tal sentido, el activismo de la primera comunidad artística latinoamericana en París es notable. Escribe Merbilhaá que entre los años 1907 y 1914 aparecen en París un total de seis revistas de tipo cultural/literarias, creadas por escritores latinoamericanos residentes en la capital francesa. Entre las que se destacan El Nuevo Mercurio (1907), Mundial Magazine (1911), la Revista de América (1912) y la Revue Sud-Américaine (1914) (Merbilhaá) Estas publicaciones tuvieron en común que fueron editadas en español, principalmente, por lo tanto, el público que deseaban forjarse estaba o entre la comunidad americana residente en París o fuera de la capital francesa, es decir, la comunidad hispano hablante (Palma).

Alejo Carpentier fue el secretario de redacción de Imán y es una de las figuras que posee la red más densa de relaciones en el ambiente intelectual y artístico en ese momento (Vásquez 2007). Es probable que su capital cultural haya sido complementario al capital monetario de Elvira de Alvear. Lo cierto es que en las páginas de Imán figuran escritores latinoamericanos, europeos y norteamericanos: León-Paul Fargue, Jean Giono, Emilio Lascano Tegui, Xul Solar, Bruno Barilli, Vicente Huidobro, Henri Michaux, Jaime Torres Bodet, Robert Desnos, Franz Kafka (traducido por Arqueles Vela), Miguel Ángel Asturias, 
Eugène Jolas (traducido por Manuel Altolaguirre), Benjamín Fondane, Xixto Martelli, Alejo Carpentier (con un fragmento de Ecué Yamba-O), Hans Arp, Boris Pilniak (traducido por Miguel Ángel Asturias), John Dos-Passos (traducido por Carlos Enríquez) o Arturo Uslar Pietri.

No parece desacertado hacer un contrapunto entre Imán, publicada en París, con otra revista publicada en el mismo año pero en Buenos Aires, Sur, así Victoria Ocampo ocupa el otro extremo de la expansión del campo de las vanguardias. A simple vista, ello se constata mediante los vínculos que Ocampo generó con los artistas e intelectuales nacionales y extranjeros. Establece con ellos lazos de amistad e intercambios que constituirá otro escenario de vanguardia en Buenos Aires. Algunos de los nombres: Rabindranath Tagore, Ernest Ansermet, Hermann Von Keyserling, Roger Caillois, Alfonso Reyes, María de Maetzu, Juan José Castro, Paul Valéry, Anna de Noailles, Pierre Drieu La Rochelle, Jules Supervielle, Adrianne Monnier, George Bernard Shaw, Waldo Frank, Eduardo Mallea, Sergei Eisenstein, Jean Cocteau, Ramón Gómez de la Serna, Pedro Henríquez Ureña, María Rosa Oliver, Leo Ferrero, Le Corbusier, Igor Stravinsky, Lev Chestov, André Malraux, Vittorio de Sica, André Gide, Jorge Luis Borges, Gabriela Mistral, Graham Greene, T.S. Eliot, Virginia Woolf, Vita Sackville-West, Albert Camus, Teilhard de Chardin, Arthur Koestler, José Ortega y Gasset, José Bianco, Octavio Paz, entre tantos otros.

El contrapunto realizado nos permite visualizar algunos corrimientos de los centros y las periferias. Esto tiene relación con la segunda cuestión que queríamos plantear. Recordemos que hasta aquí hemos argumentado sobre la manera como una revista de un solo un número alcanza un éxito. Imán se halla entre las revistas de la vanguardia, pero en un momento en que estas corrientes estéticas dejan de tener a París como único centro o en todo caso existe una diversificación de los centros. Ya ha pasado la hora del famoso debate sobre el "meridiano cultural" en el que Madrid pretendió erigirse como el centro iberoamericano, circunstancia que fue rechazada por los latinoamericanos que no toleraron tales arrebatos eurocéntricos. Por otra parte, es interesante el uso de coordenadas espaciales o de 
la física para dar nombre a las publicaciones. Aludimos concretamente a los nombres "Sur" e "Imán". Las metáforas de estos nombres poseen sentidos bien definidos (Marini Palmieri 39). En el caso de Sur, una vez que Victoria Ocampo perfila mejor el rumbo de su publicación será un puente entre la cultura americana y europea, aunque terminó siendo en un solo sentido, es decir, de Europa hacia América. (Ocampo 16) Por el contario Imán está más dispuesta a insertar lo americano en Europa, a juzgar por los textos que publica, aunque también el poder de atracción se extiende a captar de las novedades del ambiento artístico.

\section{Descubrir lo propio}

Como se ha sido dicho, Imán publica fragmentos de obras de Asturias, Uslar Pietri y Carpentier. Dos de estos fragmentos pertenecen a sendas novelas: Las lanzas coloradas de Uslar Pietri publicada en Madrid en 1931, la primera novela del venezolano. El texto viene firmado en "París, 1930". La novela será traducida al francés por Jean Cassou y editada por Gallimard en 1933. La otra novela es de Alejo Carpentier, Ecué-Yamba-Ó que se publica en 1933, en la editorial España. Comparte con la novela anterior el hecho de ser también la primera obra narrativa. La escritura de la novela se inicia en Cuba y su versión definitiva está datada como "París, enero-agosto 1933". El propio autor trabajó en la traducción, pero no llegó a publicarse la versión en francés hasta 1988. Estas primeras ediciones además incluyen información complementaria como glosarios, escuetos diccionarios de americanismo, fotografías, ilustraciones. Por último, el texto de Asturias es un cuento "En la tiniebla del cañaveral", una de sus versiones apareció en el mes de abril de 1931 en Imán y otra fechada el 22 de agosto del mismo año. El texto definitivamente será la base del capítulo VI de Hombres de maíz (una buena parte de "Venado de las siete-rozas") (Asturias). El texto dado a conocer en la revista no es sino la continuidad de un trabajo minucioso en torno al pasado precolombino que Asturias ha emprendido. Ya en 1930 había concebido en París las Leyendas de 
Guatemala, cuya primera edición será en Madrid y que tuvo dos inmediatas traducciones, la de G. Pillement y posteriormente se publica la primera edición francesa en 1932 (Corti ed.), la traducción esta vez corresponde a Francis de Miomandre. (Dumas) Estudió religiones y mitos de la América Central en la Sorbona con el profesor Georges Raynaud, cuyo resultado será una nueva edición del Popol Vuh en 1925. Como se aprecia, los tres textos son fruto del funcionamiento de la "máquina escritural" que es París, así como también se pone a funcionar la estrategia de la traducción como una vía de inserción artística en la metrópolis cultural.

Seymour Mentor realizó hace tiempo una comparación entre Asturias, Carpentier, pero el tercer escritor no es Uslar Pietri sino Agustín Yánez (Menton 33). No obstante que el tercer escritor comparado no pertenezca a la línea de nuestra argumentación, no deja de ser destacable ya que Yáñez será la bisagra hacia los años 1940 de la gran transformación de la narrativa latinoamericana. Queremos decir con esto que también él está entre los renovadores de la prosa ficcional latinoamericana. Asturias y Carpentier, de acuerdo con Menton, comparten el elemento poético. Agrega Menton:

Este elemento poético es lo que más distingue a Asturias, a Carpentier y a Yáñez de sus contemporáneos que dominaron la época de 1930 a 1945 con una literatura de marcada estampa proletaria y de relativamente poco vuelo artístico. Mientras López y Fuentes (18971967), Jorge Icaza (1906), Ciro Alegría (1909-1967) y otros escribían novelas y cuentos de protesta social, Asturias (1899), Carpentier (1904) y Yáñez (1904), que habían hecho su aprendizaje literario dentro del vanguardismo de la década de los 1920, y que habían publicado sus primeras obras antes de 1933, guardaron silencio durante unos diez años. Cuando volvieron a surgir, en la posguerra, publicaron obras verdaderamente importantes, y su fama ha seguido creciendo hasta la fecha: El señor Presidente (1946), Al filo del agua (1947), El reino de 
CATEDRAL TOMADA: Revista de crítica literaria latinoamericana / Journal of Latin American Literary Criticism

El acierto en el fracaso. La revista Imán (1931), un episodio de la historia literaria latinoamericana

este mundo (1949) y Los pasos perdidos (1953). (Menton 33 cursivas nuestras)

De manera que lo que Menton reconoce como un componente biográfico destacable es que los tres tuvieron una formación literaria determinada por el vanguardismo de la década de los 1920. Elvira de Alvear en la presentación de Imán manifiesta que en la publicación no hay ni dogmas ni capilla como tampoco expresará el carácter local. Agrega que "[L]a brújula actual del mundo entero ha perdido su imanación: no sabemos a cuál escuela corresponde nuestro concepto íntimo" (Alvear I). Más adelante escribe: "Es verdad que América Latina es un continente que encierra un enigma poético; pero en cuanto a manifestación es ya más que una esperanza.” (Alvear I) Apenas unos años antes Francisco Contreras pergeña el concepto de "mundonovismo" en París, había escrito en el Proemio a su novela El pueblo maravilloso lo siguiente:

Es menester que los novelistas se propongan en fin interpretar la humanidad integralmente [...] Pero es necesario también que procedan por síntesis, por selección, por escorzo, eliminando lo inútil y lo insignificante para construir, en lo posible, con elementos esenciales como lo hacen los líricos, a fin de entrañar significación trascendental y perdurable. Es menester, en una frase, inaugurar la Novela Integral y Lírica. (Contreras 9)

A esta poética del chileno Contreras, habría que adicionarle lo escrito por Paul Valéry en una carta a Francis de Miomandre, traductor de las "Leyendas de Guatemala" de Asturias: "En cuanto a las leyendas, me han dejado traspuesto. Nada me ha parecido más extraño -quiero decir más extraño a mi espíritu, a mi facultad de alcanzar lo inesperado- que estas historias-sueños-poemas donde se confundan tan graciosamente las creencias, los cuentos y todas las edades de un pueblo [...]. (Valéry 328) Valéry como Contreras, y tiempo después Menton ponen un énfasis 
en la naturaleza lírica de los textos aludidos que emana de ese ambiente vanguardista parisino. El lirismo en la narrativa es para Contreras directamente "la Novela Integral y Lírica", camino de los cambios en América Latina hacia el realismo mágico y lo real maravilloso.

\section{Conclusiones}

La revista Imán es un "banco de prueba" del realismo mágico y lo real maravilloso que se expresa en la renovación de la prosa narrativa que emprenden Miguel Ángel Asturias, Alejo Carpentier y Arturo Uslar Pietri. La metrópolis parisina atrae con facilidad inusitada a los artistas latinoamericanos o periféricos en general. El afán por la consagración torna a París en una máquina de escritura, por un lado, y, por el otro, la distancia con las realidades nacionales es el acicate para el descubrimiento de una identidad americana. Se produce un movimiento del centro a los márgenes, tal como lo ha dicho Trinidad Barrera. La investigadora dedica un capítulo a las renovaciones que venimos tratando titulado justamente "Surrealismo, real maravilloso y realismo mágico, otras formas de ver el continente. Arturo Uslar Pietri, Alejo Carpentier, Miguel Ángel Asturias" (Barrera). Ver la realidad continental con ojos diferentes es el saldo de la experiencia vanguardista que estos escritores dejaron plasmado en la revista.

En su ensayo sobre el realismo mágico, Uslar Pietri recuerda y sintetiza de esta manera lo ocurrido en el período en el que surge la Imán:

Por entonces, Miguel Ángel Asturias, que trabajaba en El señor Presidente, publicó sus Leyendas de Guatemala. Produjo un efecto deslumbrante; en ellas expresaba y resucitaba una realidad casi ignorada e increíble, resucitaba el lenguaje y los temas [...] en una lengua tan antigua y tan nueva que no tenía edad ni parecido. [...] Carpentier escribió su novela negra Ecue Yamba O, llena de magia 
africana y de realidad sorprendente, $[\ldots]$ yo terminé y publiqué mi primera novela, Las lanzas coloradas. Se trataba, evidentemente, de una reacción $[\ldots]$ contra la literatura descriptiva e imitativa que se hacía en la América hispana, y también reacción contra la sumisión tradicional a modas y escuelas europeas. (Uslar Pietri 136)

Tal como ha matizado Cañete Ochoa, en su tesis sobre la primera narrativa de Alejo Carpentier, estos escritores van a París no tanto a la búsqueda de la americanidad, sino que "buscaban una identidad literaria" y se dieron cuenta que "ninguna mejor que la americana", la aplicación de las fórmulas de las vanguardias era necesario pero no suficiente para alcanzar esa "identidad literaria" por medio del cambio, de tal manera que aquella "lengua tan antigua y tan nueva" de Asturias abría el camino para superar "las obras maestras del criollismo".

Por último, Imán es una empresa editorial fallida desde el punto de vista de cualquier proceso de una publicación cultural, por el hecho de que se conoce de ella un solo número. Pero hay un acierto en lo que concierne a la incorporación de los textos que participarán del cambio narrativo latinoamericano, perteneciente a tres escritores que coinciden en el París de fines de los 20 y comienzos de los 30 del siglo XX. Hecho que no tiene otros antecedentes. La novela de tono "lírico" (no es, claro está, el único rasgo destacable, pero quizás el que mejor sintetiza lo ocurrido) que estos escritores producen en la sede metropolitana constituye un paso decisivo en la superación del realismo literario vigente en América hasta entonces. Asimismo, es digno de destacarse que hay una búsqueda deliberada de hallar una identidad literaria latinoamericana. Es un impulso que mueve al cambio de algunos patrones estéticos asentados en América. La estancia parisina puso a disposición de los escritores en cuestión los elementos para la búsqueda. Tal es la importancia: el germen del surgimiento de la "nueva novela latinoamericana" se remonta a estos intentos, búsquedas, pruebas. En la consideración final de la transformación, la capital cultural como París, no deja de tener su implicancia, en virtud de que el ambiente vanguardista sirvió de marco para todas las acciones editoriales y 
textuales que habrán de impactar en la narrativa latinoamericana. Del centro a la periferia parece ser el mejor trazado del camino que se allanó en este singular episodio de la cultura literaria de América Latina.

\section{Bibliografía}

Alvear, Elvira de. “Amigo lector”. Imán, n. 1 (1931)

Asturias, Miguel Ángel. "Cap VI”. Hombres de Maíz. Guatemala: F\&G Editores, 2009.

Barrera, Trinidad. Del centro a los márgenes. Narrativa hispanoamericana del siglo XX. Sevilla: Universidad de Sevilla, 2003.

Cañete Ochoa, Jesús. Tesis "La primera narrativa de Alejo Carpentier" $<$ https://studylib.es/doc/6569184/tesis-jes\%C3\%BAs-ca\%C3\%B1eteochoa\#.W7_DEJJ37dB.gmail> Universidad de Alcalá, 2015.

Colombi, Beatriz. "Camino a la meca: esritores hispanoamericanos en París (1900-1920)". Altamirano, Carlos (dir.), Jorge Myers (ed. del vol.). Historia de los Intelectuales en América Latina. I. La ciudad letrada, de la conquista al modernismo, Buenos Aires, Katz, 2008.

Contreras, Francisco. El pueblo maravilloso. París: Agencia Mundial de Librería, 1927.

Cheymol, Marc. Miguel Ángel Asturias dans le Paris des Années folles. Grenoble: Presses Universitaires, 1987.

Dumas, Jean-Louis. “Asturias en Francia”. Revista Iberoamericana 67 (1969)

Entrevista a Carlo Ginzburg. El Comercio (Perú) 7/10/2018.

Escritores de América Latina en París. Coord. Milagros Palma. Paris: Índigo, 2007. 
Marini Palmieri, Enrique. "Cosmopolis" (1919-1921) : una 'metáfora cultural' entre Modernismo y Vanguardismo. América: Cahiers du CRICCAL, $\mathrm{n}^{\circ}$ 4-5 . Le discours culturel dans les revues latino-américaines de l'entredeux guerres, 1919-1939 (1990)

Menton, Seymour. “Asturias, Carpentier y Yáñez: Paralelismos y Divergencias.” Revista Iberoamericana 67 (1969)

Merbilhaá, Margarita. "La red de revistas latinoamericanas en París (1907-1914), un esbozo . Una mirada global sobre las revistas latinoamericanas en París (1907 - 1914): condiciones, mediaciones." Orbis Tertius, 24 (2016). 〈 http://www.orbistertius.unlp.edu.ar/article/view/OTe016 >

Müller-Bergh, Klaus, Mendonça Teles, Gilberto. Vanguardia Latinoamericana:

Historia, crítica y documentos. Tomo V, Sudamérica. Chile y países del Plata: Argentina, Uruguay, Paraguay. Madrid: Vervuert Iberoamericana, 2009.

Ocampo, Victoria, "Carta a Waldo Frank”. Sur (verano, 1931).

"Revues litteraires". $<$ http://www.revues-

\section{litteraires.com/articles.php?lng=fr\&pg=1074 >}

Rojas, Daniel Emilio. "Los latinoamericanos de París en el cambio de siglo. Sobre Die Hauptstadt Lateinamerikas (2013), de Jens Streckert”. Colombia Internacional [en línea] 2016.

\section{<http://www.redalyc.org/articulo.oa?id=81245608011>}

Rosado, Juan Antonio. "Miguel Ángel Asturias: Luz y sombras". La experiencia literaria, 14-15 (2009).

Sarlo, Beatriz. "Intelectuales y revistas: razones de una práctica". América:

Cahiers du CRICCAL, 9-10. Le discours culturel dans les revues latinoaméricaines, 1940-1970 (1992)

Siskind, Mariano. Deseos cosmopolitas. Modernidad global y literatura mundial en América Latina. Ciudad Autónoma de Buenos Aires: Fondo de Cultura Económica, 2016. 
Uslar Pietri, Arturo. "Realismo mágico." Godos, insurgentes y visionarios.

Barcelona: Seix Barral, 1990.

Valery, Paul. "Carta de Paul Valéry a Francis de Miomandre". Asturias, Miguel Ángel. Cuentos y Leyendas. Edición crítica Mario Roberto Morales (coord.) Madrid: ALLCA XX, 2000.

Vásquez, Carmen. “Alejo Carpentier en París”. Escritores de América Latina en París. Coord. Milagros Palma. Paris: Índigo, 2007. 